\title{
Association between Prior Chlamydia trachomatis Infection and Ectopic Pregnancy at a Tertiary Care Hospital in South Western Uganda
}

\begin{abstract}
Derrick Paul Mpiima (D), George Wasswa Salongo, Henry Lugobe ${ }^{D}$, Augustine Ssemujju, Olivier Mumbere Mulisya $\mathbb{D}^{D}$, Abraham Masinda, Hillary Twizerimana, and Joseph Ngonzi
\end{abstract}

\author{
Mbarara University of Science and Technology, Mbarara, Uganda \\ Correspondence should be addressed to Derrick Paul Mpiima; mpiima.paul87@gmail.com
}

Received 8 June 2017; Revised 30 November 2017; Accepted 11 December 2017; Published 1 March 2018

Academic Editor: Robert Coleman

Copyright (C) 2018 Derrick Paul Mpiima et al. This is an open access article distributed under the Creative Commons Attribution License, which permits unrestricted use, distribution, and reproduction in any medium, provided the original work is properly cited.

\begin{abstract}
Background. Increase in the number of ectopic pregnancy is attributed to increase in the incidence of pelvic infections. Chlamydia trachomatis is responsible for most of the sexually transmitted bacterial infections. If undetected and untreated, the infection can ascend to the upper genital tract and cause pelvic inflammatory disease (PID) and related sequelae (ectopic pregnancy and tubal factor infertility). Objective. To determine the association between prior Chlamydia trachomatis infection and ectopic pregnancy at Mbarara Regional Referral Hospital (MRRH). Methods. This was an unmatched case-control study carried out at MRRH involving 25 cases and 76 controls. Serological evidence of prior chlamydial infection was determined by testing for the presence of Chlamydia immunoglobulin $\mathrm{G}$ antibodies in their blood. Logistic regression was used to determine the association between prior Chlamydia trachomatis infection and also the factors associated with ectopic pregnancy. The significant level of $<0.05$ was used. Results. Chlamydia antibodies were found in $60 \%$ of patients with ectopic pregnancy and $26.3 \%$ of the controls $(p=0.002)$. The presence of Chlamydia antibodies was associated with a fourfold risk of ectopic pregnancy. Conclusion. There was a strong association between prior Chlamydia trachomatis infection and ectopic pregnancy.
\end{abstract}

\section{Introduction}

In Uganda, in the last three decades, ectopic pregnancy has assumed epidemic proportion with significant maternal morbidity, mortality, and fetal wastage (Aliya (2010)). The incidence of ectopic pregnancy is directly related to the prevalence of salpingitis. Endosalpingeal damage secondary to pelvic inflammatory disease caused by Chlamydia trachomatis infection has been found to be a major risk factor for the development of ectopic pregnancy [1]. Studies from northern and southwestern Nigeria showed macroscopic evidence of pelvic inflammatory disease at laparotomy in over $60 \%$ of patients with ectopic pregnancy [2]. Both increased incidence of $C$. trachomatis infection and the efficacy of antibiotic therapy in preventing total tubal occlusion, after an episode of salpingitis, are related to increased incidence of ectopic pregnancy [3].

In females, up to $40 \%$ of chlamydial cervicitis may ascend to the endometrium and is responsible for the etiology of endometritis and salpingitis [4]. Fallopian tube samples of patients with ectopic pregnancy have also been found positive for $C$. trachomatis deoxyribonucleic acid using the polymerase chain reaction. The frequent association between chlamydial cervicitis and the presence of vaginal clue cells or Gram stain abnormalities indicative of an overgrowth of anaerobic bacteria has led to the speculation that $C$. trachomatis alters the normal vaginal ecology, thereby setting the stage for a complex polymicrobial upper genital tract infection. 
Untreated or poorly treated chlamydial infection of the genital tract can therefore have serious long-term reproductive consequences. Late sequelae of the disease include chronic pelvic inflammatory disease, tubal blockage and infertility, chronic pelvic pain, and ectopic pregnancy $[5,6]$. Seroepidemiological studies have indicated that chlamydial infections account for a large proportion of asymptomatic genital tract infection, by demonstrating a strong link between tubal pathology and the presence of chlamydial antibodies. The chlamydial immunoglobulin $G$ antibodies are associated with the development of late sequelae and are markers for previous exposure. In chronically infected patients negative for endocervical C. trachomatis, a positive serological test may be the only indication of chlamydial involvement. Serum immunoglobulin G antibodies to Chlamydia have also been associated with tubal factor infertility and ectopic pregnancy [7].

This study therefore evaluates prior exposure to C. trachomatis in patients treated for ectopic pregnancy by determining the presence of immunoglobulin $G$ antibodies in their sera. By comparing the same with women carrying normal intrauterine pregnancy, it seeks to determine the risk association between prior C. trachomatis infection and ectopic pregnancy at Mbarara Regional Referral Hospital.

\section{Materials and Methods}

This was an unmatched case-control study that is $1: 3$ ratio of cases to controls) carried out at Mbarara Regional Referral Hospital between September 2016 and January 2017. Consecutive sampling method was used to enrol all mothers who met the inclusion criteria until the sample size was achieved. The cases were 25 consecutive women with a diagnosis of ectopic pregnancy during the study period. The control group was made up of women with confirmed uncomplicated intrauterine pregnancy, attending the antenatal clinic of MRRH. Each case of ectopic pregnancy was followed by pregnant controls attending the antenatal clinic. The sample size for this study was calculated using the formula provided in Kelsey et al. (1996) for calculating the sample size for unmatched case-control studies. After computing for the expected $10 \%$ attrition, the sample size was calculated to be 25 cases and 76 controls giving a total sample size of 102. All patients who had laparotomy for tubal ectopic pregnancy, who consented to this study and satisfied the inclusion and exclusion criteria, were recruited until the minimum sample size was obtained. The approval to conduct the study was obtained from the Department of Obstetrics and Gynecology, Faculty of Medicine Research Committee (DMS 6), MUST Research Ethics Committee (Number 21/7-16), and the Uganda National Council of Science and Technology (HS 2146). Informed consent was obtained from all respondents, and confidentiality was ensured. Study participants were identified by study codes and not their names, for issues of confidentiality. In addition, authority was sought from the office of the hospital director of MRRH to conduct the study in this institution.
Serological evidence of prior chlamydial infection was determined in both groups by examining for the presence of Chlamydia immunoglobulin $\mathrm{G}$ antibodies in their blood. Five milliliters $(5 \mathrm{ml})$ of blood was collected from the volar surface of the forearm of all the participants and emptied into clean, gold coated vacutainer. The specimen was collected from patients with ectopic pregnancy before blood transfusion and surgery and also from the control group. The blood was taken to the research laboratory (lancet laboratory) where the specimen was allowed to clot, centrifuged, and sera obtained. The sera were analyzed in batches for Chlamydia antibodies. The serological assay was done using the ImmunoComb Chlamydia trachomatis Immunoglobulin $\mathrm{G}$ kit (Orgenics, France), an indirect solid-phase enzyme immunoassay (EIA) test that quantitatively measures antibodies to Chlamydia trachomatis in human serum. The reagent test kit was brought to room temperature, and then, $10 \mu \mathrm{L}$ (microlitre) pipetted serum was assayed with reagent control samples for Chlamydia trachomatis antibodies.

The collected data were entered into a password protected computer using Microsoft excel, and data were imported into STATA 11 software for analysis. Results were presented as means with standard deviations, frequency distribution tables, and cross tables. Descriptive analysis was done for sociodemographic, sexual, and reproductive characteristic data, and tests of significance were done using chi-square test. The level of statistical significance was set at $p$ value $<0.05$. The regression logistic analysis was used to determine the association between Chlamydia trachomatis and ectopic pregnancy and also found the other factors associated with ectopic pregnancy.

\section{Results}

Majority of the participants were Banyankole, had at least primary level of education, and were residents of Mbarara. Mean age of the cases was $27.8 \pm 4.3$ and $25.2 \pm 5.9$ for controls. There were significantly more (12 (48.0\%)) single women among the cases population with ectopic pregnancy than the controls $(5(6.58 \%))(p<0.01)$ (Table 1$)$.

Table 2 shows sexual behaviour of the participants. The cases engaged in sexual intercourse at a significantly younger age than the controls $(p<0.01)$. There were more cases with multiple sexual partners compared to the control group. Previous history of pelvic inflammatory disease was obtained in $24(96.00 \%)$ among the cases. This was significantly more than $8(10.53 \%)$ among the controls $(p=0.02)$. The cases group had significantly more surgeries $13(52.00 \%)$ compared to only $6(7.89 \%)$ among the control group.

Chlamydia antibodies were found in $15(60 \%)$ and 20 (26.32\%) of the cases and controls, respectively $(p=0.02)$. The presence of Chlamydia antibodies is associated with a fourfold risk of ectopic pregnancy (OR 4.4; CI 1.70-11.48) (Table 3).

Table 4 shows that prior Chlamydia trachomatis infection, single women, and a history of previous pelvic/ abdominal surgery are independently associated with ectopic pregnancy at Mbarara Regional Referral Hospital. 
TABLE 1: Sociodemographic characteristics $(N=101)$.

\begin{tabular}{|c|c|c|c|}
\hline Characteristic & $\begin{array}{c}\text { Controls, } \\
n(\%)\end{array}$ & $\begin{array}{l}\text { Cases, } \\
n(\%)\end{array}$ & $p$ value \\
\hline \multicolumn{4}{|l|}{ Age in years } \\
\hline $16-19$ & $12(15.79)$ & $1(4.00)$ & \\
\hline $20-24$ & $38(50.00)$ & $6(24.00)$ & \\
\hline $25-34$ & $21(27.63)$ & $14(56.00)$ & 0.011 \\
\hline $35-42$ & $5(6.58)$ & $4(16.00)$ & \\
\hline Mean age & $27.8 \pm 4.3$ & $25.2 \pm 5.9$ & \\
\hline \multicolumn{4}{|l|}{ District } \\
\hline Mbarara & $68(90.67)$ & $20(80.00)$ & \\
\hline Greater Bushenyi & $4(5.33)$ & $4(16.00)$ & 0.234 \\
\hline Others & $4(4.00)$ & $1(4.00)$ & \\
\hline \multicolumn{4}{|l|}{ Residence type } \\
\hline Rural & $38(50.00)$ & $13(52.00)$ & 0.862 \\
\hline Urban & $38(50.00)$ & $12(48.00)$ & \\
\hline \multicolumn{4}{|l|}{ Tribe } \\
\hline Banyankore & $59(77.63)$ & $20(80.00)$ & \\
\hline Baganda & $5(6.58)$ & $3(12.00)$ & \\
\hline Bakiga & $7(9.21)$ & $2(8.00)$ & 0.496 \\
\hline Others & $5(6.58)$ & $0(0.00)$ & \\
\hline \multicolumn{4}{|l|}{ Level of education } \\
\hline No formal education & $2(2.63)$ & $0(0.00)$ & \\
\hline Primary education & $38(50.00)$ & $6(24.00)$ & \\
\hline Secondary education & $24(31.58)$ & $11(44.00)$ & 0.075 \\
\hline Tertiary education & $12(15.79)$ & $8(32.00)$ & \\
\hline \multicolumn{4}{|l|}{ Marital status } \\
\hline Single & $5(6.58)$ & $12(48.00)$ & 0.000 \\
\hline Married & $68(89.47)$ & $12(48.00)$ & \\
\hline Separated & $3(3.95)$ & $1(4.00)$ & \\
\hline \multicolumn{4}{|l|}{ Religion } \\
\hline Christian & $44(57.89)$ & $14(56.00)$ & 0.868 \\
\hline Moslem & $32(42.11)$ & $11(44.00)$ & \\
\hline \multicolumn{4}{|l|}{ Occupation } \\
\hline Unemployed & $13(17.33)$ & $1(4.00)$ & \\
\hline Peasant & $35(46.67)$ & $3(12.00)$ & \\
\hline Business & $21(28.00)$ & $15(60.00)$ & 0.001 \\
\hline Professional & $6(8.00)$ & $6(24.00)$ & \\
\hline \multicolumn{4}{|l|}{ Income in Uganda (shs) } \\
\hline$\leq 90,000$ & $24(31.58)$ & $24(96.00)$ & 0.000 \\
\hline$\geq 90,000$ & $52(68.42)$ & $1(4.00)$ & \\
\hline
\end{tabular}

Logistic regression model analysis of risk factors for ectopic pregnancy showed a fourfold increase in the risk of ectopic pregnancy in those with $C$. trachomatis antibodies when controlling for previous history of pelvic inflammatory disease (OR 4.9; 95\% CI 1.15-21.29).

Controlling for the effects of sociodemographic characteristics, previous history of pelvic inflammatory disease, marital status, and number of sexual partners showed that single women (OR 12.0; 95\% CI 2.21-65.32) and having
TABLE 2: Sexual and reproductive characteristics $(N=101)$.

\begin{tabular}{|c|c|c|c|}
\hline Characteristic & $\begin{array}{c}\text { Controls, } \\
n(\%)\end{array}$ & $\begin{array}{l}\text { Cases, } \\
n(\%)\end{array}$ & $p$ value \\
\hline \multicolumn{4}{|l|}{ Parity } \\
\hline 1 & $41(53.95)$ & $1(4.00)$ & \\
\hline 2 & $22(28.95)$ & $21(84.00)$ & 0.000 \\
\hline$>3$ & $13(17.11)$ & $3(12.00)$ & \\
\hline \multicolumn{4}{|l|}{ Menarche } \\
\hline$<12$ years & $2(2.67)$ & $1(4.00)$ & \\
\hline $12-14$ years & $37(49.33)$ & $21(84.00)$ & 0.006 \\
\hline$>14$ years & $36(48.00)$ & $3(12.00)$ & \\
\hline \multicolumn{4}{|l|}{ Coitarche } \\
\hline$<19$ years & $46(60.00)$ & $25(100.00)$ & 0.000 \\
\hline$>19$ years & $30(40.00)$ & $0(0.00)$ & \\
\hline \multicolumn{4}{|c|}{ Multiple sexual partners } \\
\hline No & $57(75.00)$ & $11(44.00)$ & \\
\hline Yes & $19(25.00)$ & $14(56.00)$ & 0.004 \\
\hline \multicolumn{4}{|c|}{ Induced abortion } \\
\hline None & $74(97.37)$ & $20(80.00)$ & \\
\hline $1-4$ & $2(2.63)$ & $5(20.00)$ & 0.003 \\
\hline \multicolumn{4}{|c|}{ History of previous PID } \\
\hline No & $68(89.47)$ & $1(4.00)$ & \\
\hline Yes & $8(10.53)$ & $24(96.00)$ & 0.002 \\
\hline \multicolumn{4}{|c|}{$\begin{array}{l}\text { History of puerperal/ } \\
\text { postabortal sepsis }\end{array}$} \\
\hline No & $75(98.68)$ & $24(96.00)$ & \\
\hline Yes & $1(1.32)$ & $1(4.00)$ & 0.403 \\
\hline \multicolumn{4}{|c|}{$\begin{array}{l}\text { History of abdominal/pelvic } \\
\text { surgery }\end{array}$} \\
\hline No & $70(92.11)$ & $12(48.00)$ & \\
\hline Yes & $6(7.89)$ & $13(52.00)$ & 0.000 \\
\hline \multicolumn{4}{|c|}{ History of IUCD usage } \\
\hline No & $73(97.33)$ & $24(96.00)$ & \\
\hline Yes & $2(2.67)$ & $1(4.00)$ & 0.735 \\
\hline
\end{tabular}

Table 3: Confirmed Chlamydia trachomatis IgG antibodies in both controls and cases.

\begin{tabular}{lccc}
\hline Chlamydia IgG antibodies & $\begin{array}{c}\text { Control, } \\
n(\%)\end{array}$ & $\begin{array}{c}\text { Cases, } \\
n(\%)\end{array}$ & $p$ value \\
\hline Negative & $56(73.67)$ & $10(40)$ & \\
Positive & $20(26.32)$ & $15(60)$ & $\mathbf{0 . 0 0 2}$ \\
\hline
\end{tabular}

a history of previous abdominal/pelvic surgery (OR 6.9; 95\% CI 1.47-32.98) were shown to be more likely to be associated with ectopic pregnancy as well.

\section{Discussion}

Serum immunoglobulin $\mathrm{G}$ antibodies have been associated with endosalpingeal damage and ectopic pregnancy resulting from pelvic inflammatory disease $[8,9]$. In this study, the prevalence of chlamydial antibodies was significantly higher 
TABLE 4: Factors associated with ectopic pregnancy at multivariate analysis.

\begin{tabular}{|c|c|c|c|c|}
\hline \multirow{2}{*}{ Variable } & \multicolumn{2}{|c|}{ Univariable } & \multicolumn{2}{|c|}{ Multivariable } \\
\hline & OR $(95 \% \mathrm{CI})$ & $p$ value & $\mathrm{aOR}(95 \% \mathrm{CI})$ & $p$ value \\
\hline \multicolumn{5}{|c|}{ Chlamydia IgG antibodies } \\
\hline No & 1.0 & & 1.0 & \\
\hline Yes & $4.4(1.70-11.48)$ & 0.0019 & $4.9(1.15-21.29)$ & 0.0019 \\
\hline \multicolumn{5}{|c|}{ Marital status } \\
\hline Single & $13.6(4.05-45.62)$ & 0.0000 & $12.0(2.21-65.32)$ & 0.0026 \\
\hline Married & 1.0 & & 1.0 & \\
\hline Separated & $1.8(0.18-19.70)$ & & $0.6(0.04-8.48)$ & \\
\hline \multicolumn{5}{|l|}{ Parity } \\
\hline 1 & 1.0 & & 1.0 & \\
\hline 2 & $39.1(4.92-310.73)$ & & $24.9(1.47-205.98)$ & \\
\hline$>3$ & $9.4(0.90-98.96)$ & 0.0000 & $6.9(1.47-32.98)$ & 0.3752 \\
\hline \multicolumn{5}{|l|}{ Menarche } \\
\hline$<12$ years & 1.0 & & 1.0 & \\
\hline $12-14$ years & $1.1(0.09-13.27)$ & 0.0031 & $3.4(0.77-14.82)$ & 0.2796 \\
\hline$>14$ years & $0.1(0.01-2.41)$ & & $1.1(0.11-11.50)$ & \\
\hline \multicolumn{5}{|l|}{ Coitarche } \\
\hline$<19$ years & $0.6(0.02-0.34)$ & 0.0000 & $0.9(0.37-2.28)$ & 0.8622 \\
\hline$>19$ years & 1.0 & & 1.0 & \\
\hline \multicolumn{5}{|c|}{ Multiple sexual partners } \\
\hline No & 1.0 & & 1.0 & \\
\hline Yes & $3.8(1.48-9.82)$ & 0.0051 & $3.1(0.18-11.88)$ & 0.4376 \\
\hline \multicolumn{5}{|c|}{ Induced abortion } \\
\hline None & 1.0 & & 1.0 & \\
\hline $1-4$ & $9.2(1.66-51.27)$ & 0.0067 & $7.0(0.43-46.68)$ & 0.8681 \\
\hline \multicolumn{5}{|c|}{ History of abdominal/pelvic surgery } \\
\hline No & 1.0 & & 1.0 & \\
\hline Yes & $12.6(4.02-39.71)$ & 0.0001 & $6.9(1.47-32.98)$ & 0.0000 \\
\hline \multicolumn{5}{|c|}{ History of previous PID } \\
\hline No & 1.0 & & 1.0 & \\
\hline Yes & $104(24.23-171.5)$ & 0.0000 & $85(33.14-169.4)$ & 0.5689 \\
\hline
\end{tabular}

(60.0\%) in patients with ectopic pregnancy than in women with intrauterine pregnancy $(26.32 \%)$. This finding confirms the report of other researchers that patients with ectopic pregnancy are more likely to have immunoglobulin $G$ antibodies against $C$. trachomatis when compared with women with intrauterine pregnancy $[4,9]$. This suggested relationship was further strengthened by the finding in this study of a fourfold increase in the risk of ectopic pregnancy in women with chlamydial antibodies. The prevalence of prior C. trachomatis infection, as evidenced by the presence of chlamydial antibodies in this and other studies, underscores the reason why ectopic pregnancy has remained a major complication of reproductive health of women and why the incidence is increasing in parallel with the rise in the rate of chlamydial infection [10]. This study also found that women with ectopic pregnancy were more likely to be single, corroborating the findings in another Nigerian study [11]. This can be explained by the fact that single women are more likely to have multiple sexual partners than married women. In examining the risk factors for Chlamydia infection among patients with ectopic pregnancy and normal pregnancy, this study looked at the sexual and reproductive characteristics of both groups. The results of univariate analysis showed that women with ectopic pregnancy engaged in sexual intercourse at a significantly younger age than women with intrauterine pregnancy. This finding is in line with previous studies which linked early coitarche with Chlamydia trachomatis infection [12]. Adolescents are prone to sexually transmitted disease (STD) because of high risk sexual behaviour. Biologically, the adolescents are particularly at risk of STD because the columnar epithelium, which is susceptible to Chlamydia and gonococcal organisms, extends from the endocervical canal to the ectocervix making it fully exposed to pathogens. They also have difficulties using barrier methods of contraception and may have less access to STD care because of limited facilities, negative peer pressure, concealment, and restrictive policies especially in the developing countries [13]. Previous history of pelvic inflammatory disease was significantly higher in patients with ectopic pregnancy when compared with women with 
normal pregnant controls. This agrees with the findings of previous studies in this regard [8]. In contrast to other studies [8], this study found that induced abortions were relatively low in women with ectopic pregnancy and did not have any association with ectopic pregnancy. This could be explained by the small number of participants in this study who had a history of induced abortions, and therefore it was difficult to assess statistical difference with such a small number.

In our study, previous history of abdominal/pelvic surgery was associated with ectopic pregnancy and this compares with studies done in other areas [14]. This could be explained by the fact that previous surgery in the pelvic area or on the tubes can cause adhesions and impede the egg's movement causing implantation in the tubes and other sites.

However, when these were subjected to logistic regression model (multivariate) analysis, patients with Chlamydia antibodies showed a fourfold increase in the risk of ectopic pregnancy when controlling for previous history of pelvic inflammatory disease. In addition, the multivariate analysis revealed that women with a history of previous abdominal/ pelvic surgery and those who were single were significantly associated with ectopic pregnancy.

\section{Conclusion}

This study has shown that a greater proportion of women with ectopic pregnancy had serological evidence of prior C. trachomatis infection than women with intrauterine pregnancy. It also demonstrated a fourfold risk association between prior C. trachomatis infection and ectopic pregnancy. Furthermore, being single and having a history of previous abdominal/pelvic surgery were positively associated with ectopic pregnancy. There is therefore a need for the sexual reproductive health division in the $\mathrm{MoH}$ to strengthen/ improve sex education and for prompt and effective treatment of sexually transmitted infections.

\section{Conflicts of Interest}

The authors declare that they have no conflicts of interest.

\section{Acknowledgments}

The authors thank all the participants and the staff of the Department of Obstetrics and Gynecology of MRRH and the staff of Lancet Laboratories for their unwavering support during this study. Sponsorship was by my father who genorously provided me with the funds and finacial assistance to carry out this research. He is called Eng. Joseph K. Kabanga.

\section{References}

[1] D. H. Amoko and G. A. Buga, "Clinical presentation of ectopic pregnancy in Transkei, South Africa," East African Medical Journal, vol. 72, no. 12, pp. 770-773, 1995.
[2] P. Thonneau, Y. Hijazi, N. Goyaux, T. Calvez, and N. Keita, "Ectopic pregnancy in Conakry, Guinea," Bulletin of the World Health Organization, vol. 80, pp. 365-370, 2002.

[3] World Health Organization, Global and Regional Estimates of Violence against Women: Prevalence and Health Effects of Intimate Partner Violence and Non-Partner Sexual Violence, World Health Organization, Geneva, Switzerland, 2013.

[4] World Health Organization, UNAIDS, and UNPO, Towards Universal Access: Scaling Up Priority HIV/AIDS Interventionsin the Health Sector, Progress report, 2010, World Health Organization HIV/AIDS Department, Geneva, Switzerland, 2010.

[5] F. Kamwendo, "Epidemiology of ectopic pregnancy during a 28 year period and the role of pelvic inflammatory disease," Sexually Transmitted Infections, vol. 76, no. 1, pp. 28-32, 2000.

[6] M. Okunlalo, K. M. Okonikoko, A. S. Adeyemi, and F. A. B. Adeyeni-Doro, "Chlamydia serology and ectopic pregnancy in Ibadin," Nigerian Medical Practitioner, vol. 55, no. 1-2, 2009.

[7] B. Andersen, L. Østergaard, E. Puho, M. V. Skriver, and H. C. Schønheyder, "Ectopic pregnancies and reproductive capacity after Chlamydia trachomatis positive and negative test results: a historical follow-up study," Sexually Transmitted Diseases, vol. 32, no. 6, pp. 377-381, 2005.

[8] J. Den Hartog, "The role of chlamydia genus-specific and species-specific IgG antibody testing in predicting tubal disease in subfertile women," Human Reproduction, vol. 19, no. 6, pp. 1380-1384, 2004.

[9] A. Moses, A. I. Munir'deen, F. A. Adegboyega, and J. A. Abdulgafar, "A study of serological evidence of prior chlamydia trachomatis infection in patients with ectopic pregnancy in Ilorin Nigeria," European Journal of Scientific Research, vol. 16, pp. 461-466, 2016.

[10] A. Adewunmi, O. Orekoya, K. Rabiu, and T. Ottun, "The association between Chlamydia trachomatis and ectopic pregnancy in Lagos, Nigeria-a case control study," Open Journal of Obstetrics and Gynecology, vol. 5, no. 2, pp. 115-122, 2015.

[11] J. Musa, P. H. Daru, J. T. Mutihir, and I. A. Ujah, "Ectopic pregnancy in Jos Northern Nigeria: prevalence and impact on subsequent fertility," Nigerian Journal of Medicine, vol. 18, no. 1, pp. 35-38, 2008.

[12] M. Maccato, R. Estrada, H. Hammill, and S. Faro, "Prevalence of active Chlamydia trachomatis infection at the time of exploratory laparotomy for ectopic pregnancy," Obstetrics \& Gynecology, vol. 79, no. 2, pp. 211-213, 1992.

[13] J. Coste, J. Bouyer, S. Ughetto et al., "Ectopic pregnancy is again on the increase. Recent trends in the incidence of ectopic pregnancies in France (1992-2002)," Human Reproduction, vol. 19, no. 9, pp. 2014-2018, 2004.

[14] K. T. Barnhart, M. D. Sammel, C. R. Gracia, J. Chittams, A. C. Hummel, and A. Shaunik, "Risk factors for ectopic pregnancy in women with symptomatic first-trimester pregnancies," Fertility and Sterility, vol. 86, no. 1, pp. 36-43, 2006. 


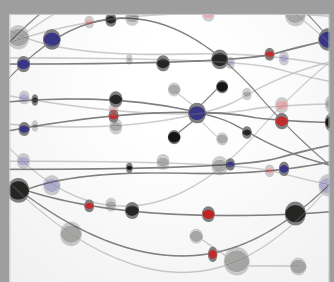

The Scientific World Journal
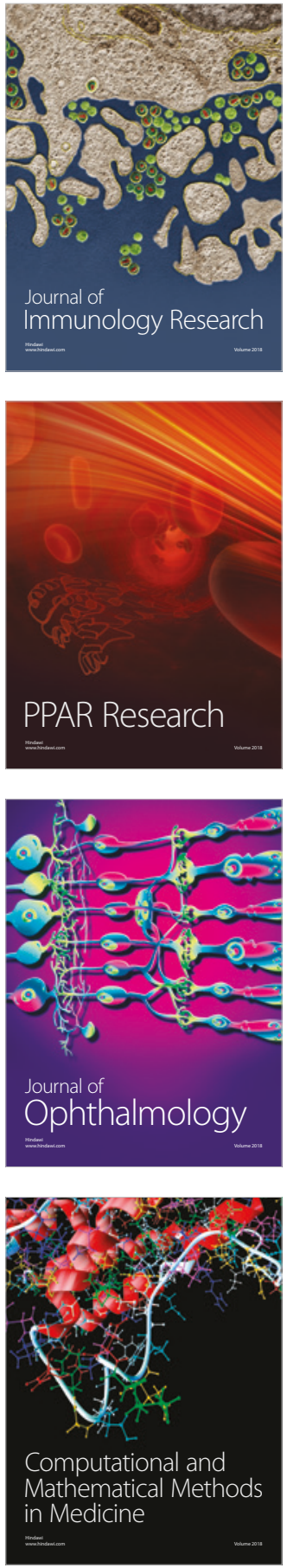

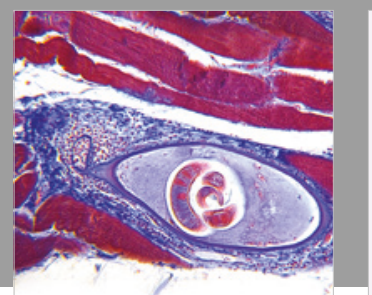

Gastroenterology Research and Practice

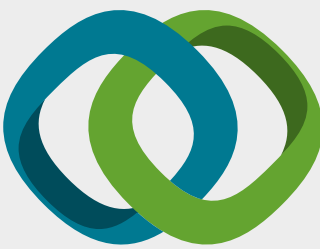

\section{Hindawi}

Submit your manuscripts at

www.hindawi.com
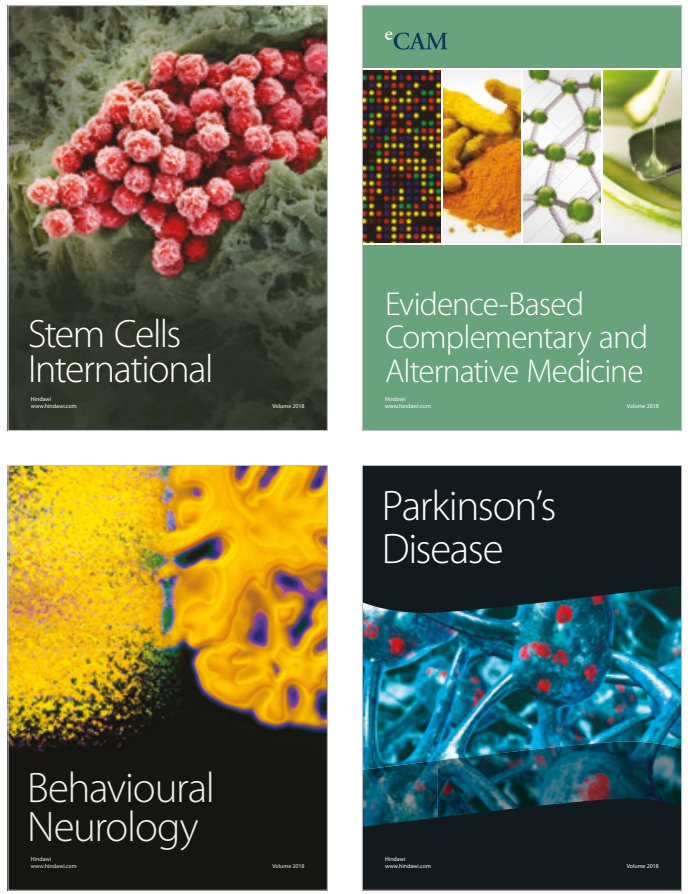

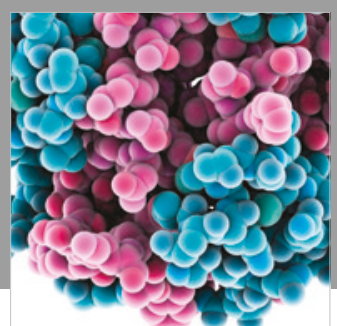

ournal of

Diabetes Research

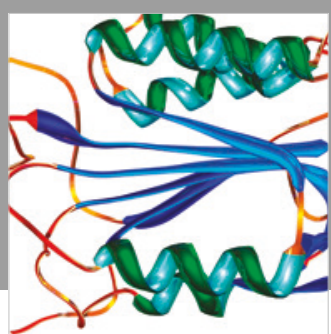

Disease Markers
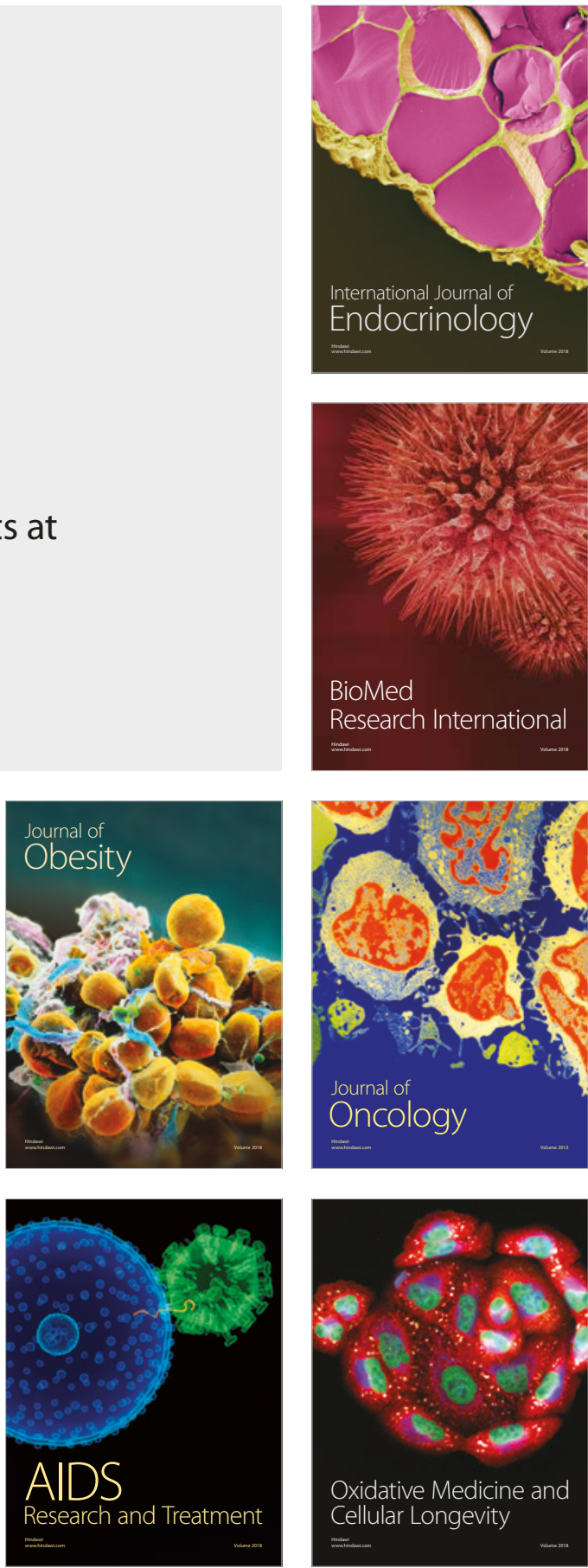